\title{
Os emaranhados da Comunicação pelas noções de campo, ciência e interdisciplinaridade
}

\author{
The tangles of Communication by the notions of field, science and \\ interdisciplinarity
}

\section{Los enredos de la comunicación por las nociones de campo, ciência y interdisciplinariedad}

\author{
Rodrigo Gabrioti \\ Escola Superior de Administração, Marketing e Comunicação de Sorocaba - ESAMC - Brasil \\ ORCID: https://orcid.org/0000-0001-6745-3600 \\ Endereço currículo Plataforma Lattes: http://lattes.cnpq.br/3018929004235747 \\ E-mail: rgabrioti@hotmail.com
}

\begin{abstract}
Resumo: Os impasses conceituais da Comunicação passam por campo, ciência e interdisciplinaridade. Por meio da revisão bibliográfica, retomamos esses postulados e defendemos que a Comunicação é protagonista diante de outros saberes pela linguagem. $\mathrm{O}$ excesso de literatura estrangeira adotada, no Brasil, exige um repensar a respeito das referências bibliográficas, função que cabe a quem forma os novos pesquisadores. A falta de autorreflexão impede o potencial produtivo de novas teorias que poderiam renovar os paradigmas ainda mais quando novas práticas tecnológicas se apresentam na atualidade. Por fim, apontamos por que o campo prevalece, a interdisciplinaridade não é opção e a Comunicação ainda não é uma Ciência. Um artigo que convida ao debate - necessário - da Área.
\end{abstract}

Palavras-chave: Comunicação. Campo. Ciência.

\begin{abstract}
The conceptual impasses of Communication go through the field, science and interdisciplinarity. Through bibliographic review, we return to these postulates and defend that Communication is the protagonist in the face of other knowledge through language. The excess of foreign literature adopted in Brazil requires a rethinking of bibliographic references, a role that is up to those who form new researchers. The lack of self-reflection prevents the productive potential of new theories that could renew the paradigms even more when new technological practices are presented today. Finally, we point out why the field prevails, interdisciplinarity is not an option and Communication is not yet a Science. An article that invites the debate - necessary - of the Area.
\end{abstract}

Keywords: Communication. Field. Science. 


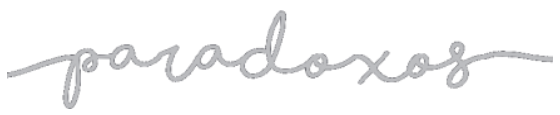

Resumen: Los impases conceptuales de la Comunicación pasan por el campo, la ciencia y la interdisciplinariedad. A través de la revisión bibliográfica, volvemos a estos postulados y defendemos que la Comunicación es la protagonista frente a otros conocimientos a través del lenguaje. El exceso de literatura extranjera adoptada en Brasil requiere un replanteamiento de las referencias bibliográficas, un papel que corresponde a quienes forman nuevos investigadores. La falta de autorreflexión impide el potencial productivo de nuevas teorías que podrían renovar los paradigmas todavía cuando se presentan nuevas prácticas tecnológicas en la actualidad. Finalmente, señalamos por qué prevalece el campo, la interdisciplinariedad no es una opción y la Comunicación todavía no es una ciencia. Un artículo que invita al debate - necesario - del Área.

Palabras-clave: Comunicación. Área. Ciencia.

\section{Campo e Interdisciplinaridade}

Se existe amadurecimento no conhecimento produzido em Comunicação, existe dificuldade em situar definitivamente seu posicionamento ontológico/taxionômico. Discutese tanto sobre sua não cientificidade e pouco se atribui à construção dos mais diversos sentidos da vida em sociedade e sua simbologia entre os mais diferentes níveis de conhecimento. Muitos apontam que esse fator complicador está na interdisciplinaridade.

$\mathrm{Na}$ visão de Wilhelm Dilthey (2010), esses impasses conceituais se pormenorizariam porque todo posicionamento é válido. Falar que a Comunicação não é ciência; que não dispõe de teorias específicas; que é processo de transmissão... encontra sentido nesse pressuposto. Se as posições são válidas, a nossa é sobre o protagonismo da Comunicação - que operando pela linguagem - se torna conhecimento primeiro diante de outros saberes.

Para a discussão destes princípios, trazemos Pierre Bourdieu (1983), Gastón Bachelard (1996; 2004), Edgar Morín (2010) e Rolando García (2006), entre outros. Bourdieu trata o campo científico como espaço de luta concorrencial onde integrantes de determinado território estão munidos de capacidade técnica e poder social.

\footnotetext{
Aqueles que estão à frente das grandes burocracias científicas só poderão impor sua vitória como uma vitória da ciência se forem capazes de impor uma definição de ciência que suponha que a boa maneira de fazer ciência implica a utilização de serviços de uma grande burocracia científica, provida de créditos, de equipamentos técnicos poderosos, de uma mão-de-obra abundante. (BOURDIEU, 1983, p. 124)
} 
O campo da Comunicação segue condicionado à tendência e ao costume de reproduzir as correntes teóricas hegemônicas funcionalistas estadunidenses e críticas europeias. Em contraste a isso, Jorge González (2012) propõe o reprocessamento de leituras, ainda decorrentes da nossa colonização, que valorizam o alheio e depreciam o próprio, outorgando assim reconhecimento ao que é de fora.

Esta é uma realidade. Em nossa pesquisa de Doutorado ${ }^{1}$, propusemos a construção taxionômica da Área da Comunicação, a partir de 912 pesquisas fomentadas pela Fundação de Amparo à Pesquisa do Estado de São Paulo (FAPESP), observando os anos de 1992 a 2016. Entre os indicadores analisados, estava a nacionalidade dos autores referenciados. Considerando apenas as Bolsas de Estudo no Brasil, se observa²:

Tabela 1 - Nacionalidade de referências bibliográficas

\begin{tabular}{|c|c|c|c|}
\hline CATEGORIA & CITAÇÕES & BRASILEIROS & ESTRANGEIROS \\
\hline Inic. Científica & 64 & 19 & $\mathbf{4 0}$ \\
& & $(29,69 \%)$ & $\mathbf{( 6 2 , 5 4 \% )}$ \\
\hline Mestrado & 83 & 10 & $\mathbf{( 8 4 , 3 4 \% )}$ \\
\hline Doutorado & 69 & $(12,05 \%)$ & $\mathbf{5 5}$ \\
& & $(15,94 \%)$ & $\mathbf{( 7 9 , 7 1 \% )}$ \\
\hline Pós-Doutorado & 34 & $(11,76 \%)$ & $\mathbf{3 0}$ \\
& & $(\mathbf{8 8 , 2 4 \% )}$ \\
\hline
\end{tabular}

Fonte: Biblioteca Virtual da FAPESP

A situação demonstrada, na tabela, mais os apontamentos de González (2012), demonstra o predomínio da literatura estrangeira. O uso de autores clássicos ou emergentes dá a conotação de "enriquecimento" à pesquisa sem necessariamente

\footnotetext{
${ }^{1}$ A tese "A FAPESP e a Ciência da Comunicação: Legitimação, Contribuição e Construção da Área" (2018) foi defendida em 25 de abril de 2018, na Universidade Metodista de São Paulo. A discussão neste artigo, inclusive, é um recorte desta tese.

${ }^{2}$ Estão considerados apenas os números de autores citados. A totalidade pode não ser exata porque alguns pesquisadores não informaram a nacionalidade de algumas referências utilizadas. 


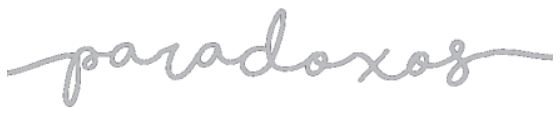

enfatizar o que diz Paul Feyerabend (2010) sobre a utilidade e a finalidade do conhecimento. Segundo ele, muitos fatos estão enterrados em publicações científicas, manuais, cartas e discos rígidos. Na sua visão, os autores de um campo precisam se ler mais atentamente para certas descobertas não se revelarem por acidente.

Um repensar bibliográfico cabe, principalmente, aos orientadores de novos pesquisadores para refletir: (1) Que pesquisadores formam? (2) Que capital científico constroem e em que posição os colocam a partir das leituras indicadas?

[...] uma sociologia científica da ciência (e a sociologia científica que ela contribui para tornar possível) só pode constituir-se com a condição de perceber claramente que às diferentes posições no campo científico associam-se representações da ciência, estratégias ideológicas disfarçadas em tomadas de posições epistemológicas através das quais os ocupantes de uma posição determinada visam justificar sua própria posição e as estratégias que eles colocam em ação para mantêla ou melhorá-la e para desacreditar, ao mesmo tempo, os detentores da posição oposta e suas estratégias. (BOURDIEU, 1983, p. 154)

Ainda sobre o campo, Craig Calhoun (2012) entende a Comunicação sob esta gênese como fator identitário para alunos, pessoas de fora, professores e até mesmo financiadores, com vistas à criação de uma preocupação comum capaz de sustentar um engajamento de problemas teóricos e práticos ou de projetos.

\begin{abstract}
A coerência em um campo como a Comunicação não precisa ser ancorada em nenhum plano miraculoso ou em um método comum. Tal coerência deve surgir associada ao resultado de inúmeras conexões específicas entre linhas de pesquisa, subcampos, práticas profissionais e compromissos públicos sem que haja um conjunto único de regras que expliquem ou organizem todos estes pontos. É extremamente importante fazer tais conexões intelectuais, e isso é necessário para assumir grandes questões que são importantes para o trabalho de muitos subcampos. (CALHOUN, 2012, p. 295)
\end{abstract}

Em algum sentido, isto dialoga com José Marques de Melo (2014) na perspectiva da tensa questão do objeto da Comunicação, visto pelos estadunidenses como algo do processo ou do suporte e, pelos europeus, como algo relacionado ao conteúdo. Marques de Melo (2014) diz que sem a integração dos pares e a troca de ideias que contribuam com a mudança do indivíduo, não há sentido produzir as demandas de cada campo do conhecimento. E que, no caso da Comunicação, o objeto de pesquisa vive na sombra, sem transparência, mesmo com uma comunidade que o estude.

Em relação à interdisciplinaridade, Braga (2011) diz que a Comunicação perde legitimidade pelos entrecruzamentos que falseiam a propriedade do campo e delimitam fronteiras onde o conhecimento pode intervir. 
O conceito da interdisciplinaridade pode significar duas coisas: a primeira corresponde à percepção de que um campo de estudos hoje se vê inevitavelmente atravessado por dados, conhecimentos, problemas e abordagens concebidos e desenvolvidos em outras disciplinas e/ou tecnologias. Nesse caso, todos os campos de conhecimento são "interdisciplinares", ou seja, não têm existência isolada, estanque. (BRAGA, 2011, p. 63)

Ao transitar pela interdisciplinaridade, Edgar Morin (2010) aponta que "Cada disciplina pretende primeiro fazer reconhecer sua soberania territorial, e, à custa de algumas magras trocas, as fronteiras confirmam-se em vez de se desmoronar" (MORIN, 2010, p.135). Além disso, define: “A ciência nunca teria sido ciência se não tivesse sido transdisciplinar (sic)”. (MORIN, 2010, pp. 135-136). Esta afirmação foi contestada por José Marques de Melo, em entrevista à edição 201 da Revista Pesquisa FAPESP. O professor declarou que a Comunicação não é uma área autônoma de pesquisa por incorporar contribuições das demais ciências.

A noção conceitual sobre o interdisciplinar, para Rolando García (2006), parte do equívoco de integração disciplinar porque nenhuma pesquisa tem a capacidade de integrar disciplinas diferentes. Na visão dele, geralmente um fenômeno ou processo está sob domínio de uma ciência, explicado pela teoria de outra. E cada Área das Ciências Sociais se integra com suas características peculiares a uma mesma pergunta de pesquisa.

Independientemente de las articulaciones que han sido constituyentes entre disciplinas correspondientes a ciertos domínios diferenciados, en los domínios cuyas fronteras son mucho más permeables, las relaciones entre disciplinas han dado lugar a reconceptualizaciones generales de los fenómenos involucrados en el domínio en cuestión. (GARCÍA, 2006, p. 27)

A professora Maria Immacolata Vassalo de Lopes (2003) também transita pela interdisciplinaridade propondo uma dimensão de síntese disciplinar e se preocupa com a tensão do objeto que leva às problemáticas metodológicas. Durante o $40^{\circ}$ Congresso Brasileiro de Ciências da Comunicação, INTERCOM 2017, em Curitiba (PR), ela alertou para a inexistência de uma autorreflexão do campo da Comunicação, o que pode levar aos sintomas da imaturidade do corpo teórico e de crise das heranças científicas, no Brasil e América Latina.

Em verdade, nossa Área aceita muitos daqueles que transportam objetos de outros campos do conhecimento para a Comunicação. Isto já foi questionado por Anamaria Fadul, na edição 211 da Revista Pesquisa FAPESP, em 2013. 
objeto e de uma metodologia. A transversalidade é meio assustadora: ela só é natural a partir de um objeto definido. (FADUL, 2013, p. 78)

Isto coincide com o que Calhoun (2012) chama de colagem não coerente, não facilmente teorizável, com muito trabalho para se manter. Evidências assim formam o que ele considera enganoso ou contraproducente. Para nós, um exercício arriscado e de perda de identidade da Comunicação. A interdisciplinaridade só faz sentido se organizada e vista pelo ângulo da nossa Área. Um exercício que todos devem fazer, pois, a sedução é grande, haja vista - como aponta Calhoun (2012) -, a fragilidade das linhas de pesquisa, o alto índice de migração para a Comunicação e a concorrência, inclusive, de associações profissionais e científicas, além das práticas atravessadas pelas tecnologias.

\section{Noções de Ciência}

Há três séculos, o conhecimento científico não faz mais do que provar suas virtudes de verificação e de descoberta em relação a todos os outros modos de conhecimento. Morin (2010) classifica a ciência em elucidativa (quando resolve enigmas e dissipa mistérios) e enriquecedora (por permitir a satisfação das necessidades sociais que desabrocham a civilização). Conceber e compreender a ambivalência propõem uma complexidade intrínseca encontrável, no cerne da ciência, cuja superespecialização, ele critica por enclausurar ou fragmentar o saber.

Ao considerar todas as ciências, inclusive as físicas e biológicas, como sociais, o autor aponta também que o conhecimento científico é algo que não se conhece. "Essa ciência, que desenvolveu metodologias tão surpreendentes e hábeis para aprender todos os objetos a ela externos, não dispõe de nenhum método para se conhecer e se pensar". (MORIN, 2010, p. 20). Ele caminha para uma definição de que a verdade objetiva da ciência escapa a todo cuidado científico, pois, a ciência é o próprio posicionamento, um campo sempre aberto onde se combatem não somente as teorias, mas os princípios de explicação com as visões de mundo. Alega que a ciência não seria considerada pura e simples "ideologia" social porque há sempre um diálogo incessante no campo da verificação empírica com o mundo dos fenômenos.

Sobre fazer ciência na contemporaneidade, Morin (2010) aponta que o novo saber científico é feito para ser depositado nos bancos de dados e para ser usado de acordo com 


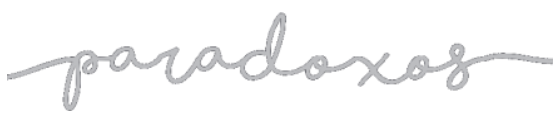

Os emaranhados da Comunicação pelas noções de campo, ciência e interdisciplinaridade

GABRIOTI, 2020

os meios e seguindo as decisões das potências. Isto é, inclusive, resultado da ação humana, já que a atividade científica, ao ser iniciada, escapa das mãos de seu iniciador para entrar no jogo das interações múltiplas, próprias da sociedade. “[...] a visão científica clássica elimina a consciência, elimina o sujeito, elimina a liberdade em proveito de um determinismo". (MORIN, 2010, p.129). A Ciência é uma consequência de realidades construídas, praticamente um exercício de autorreflexão, ao se atrelar a um ambiente formado por indivíduos, em constante revisão, que buscam contribuir com um novo ponto de vista em face de tantos outros testados a favor do conhecimento.

Não é segredo nem desconhecimento que toda comunicação é intencional. Vivências se desencadeiam e colocam, em condições de igualdade, Comunicação e Ciência. Como admite Dilthey (2010), as Ciências Humanas, além da vivência, encampam expressão e compreensão, proporcionando um sistema social entendido como sistema cultural.

A compreensão matemática da Comunicação, que deu origem aos marcos teóricos do campo, tinha como princípio a condição de que dois pontos distantes estabelecessem uma comunicação cujo efeito compreendia o êxito da mensagem transitada por um canal. E assim a corrente estadunidense assumia a perspectiva dos efeitos da mensagem, pelos emissores, que trabalhavam com a reação dos receptores. Já as correntes europeias são racionais, com ideologias e hegemonia, que fazem da cultura um bem a ser consumido. Trata-se do princípio da indústria cultural.

Anos depois, a perspectiva latino-americana da Comunicação se centraliza nas experiências culturais como cerne de realização. Até pela natureza de colonizada, a América Latina reúne pesquisadores críticos à ecologia midiática com o propósito de oferecer um novo olhar ao estatuto paradigmático das teorias. Essas tessituras sugerem a complexidade, no sentido dado por Morín (2010), de procura viciosa da obscuridade. Considerando isso, a imprecisão conceitual torna a Comunicação, complexa.

Muniz Sodré (2014) também discute uma noção científica à Comunicação. Ele parte das relações e do comum para elencar três níveis. No primeiro, o relacional, a ideologia se produz e se reproduz, no sistema social, por meio de fluxos com trocas dominantes em uma conformidade do real com as representações estabelecidas. Neste nível operativo, o autor destaca a presença da mídia como instrumento capaz de auxiliar a interpretação do mundo. Pensando isso na prática: o Jornalismo Colaborativo tem como sentido simbólico a participação do leitor ou telespectador, via tecnologia, no processo de produção noticiosa. Mas até que ponto isso existe e se dá? O indivíduo que DOI: http://doi.org/10.14393/par-v5n1-2020-53796 - Paradoxos, Uberlândia, v. 5, n. 1, p. 5-19, jan./jun. 2020 


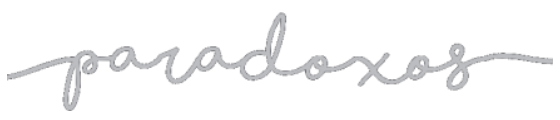

Os emaranhados da Comunicação pelas noções de campo, ciência e interdisciplinaridade

GABRIOTI, 2020

participa com conteúdo atende um pedido que não necessariamente é pautado pela colaboração, e sim, por um modo de informar algum fato que os jornalistas ainda desconhecem ou que resulte em cobertura jornalística.

O segundo nível é o da vinculação. O ser é atravessado por uma exterioridade ao comum, é pressionado para fora de si e dividido ontologicamente. Sodré (2014) entende isso como a ocupação do lugar do outro na compreensão simbólica de uma dada estrutura. O sujeito constrói vínculos, a partir dos fatos, e a compreensão vem desse novo acontecimento gerado.

O terceiro nível é o crítico-cognitivo, ou simplesmente, metacrítico que envolve a redescrição da pesquisa enquanto modo ativo de conhecimento. As mutações socioculturais exigem um autoquestionamento dos momentos comunicativos. Sodré (2014) aponta isto como releitura à luz das mutações que colocam, no mesmo plano de discussão, as conexões teóricas da Comunicação, que não podem ser satisfeitas pelas agregações multidisciplinares.

Quando sugerimos a Comunicação como protagonista das relações comuns, encontramos respaldo no que Sodré (2014) chama de hermenêutica tradutora, partindo de problemáticas nas quais se realizam os discursos possíveis do pensamento social. Logo, a Comunicação é mais que transmissão ou conhecimento de passagem. É uma hermenêutica legitimada pelo seu estatuto conceitual.

Em todo esse panorama, Sodré (2014) postula às Ciências da Comunicação, premissas de Ciência Social, por produzirem valor social, cultural e político que resultam na elaboração de novas formas do comum. É impossível abandonar a ideia de socialização, mesmo com as noções de espaço e de tempo encurtadas, planas e instáveis na atualidade. A formação científica do comum que Sodré (2014) formula tem como método as relações humanas e suas trocas simbólicas.

\section{A pesquisa em Comunicação e o discurso das teorias}

São três as condições, exaltadas por Marques de Melo (2014), como direcionamento teórico: reflexão, sistematização e atualização. Quando cruzamos esses preceitos com os de Feyerabend (2010, p.35), percebemos a elitização da dimensão teórica. 
A abordagem teórica usa o entendimento, mas não o entendimento das partes envolvidas. Grupos especiais, filósofos e cientistas entre eles, estudam os valores conflitantes, organizam-nos em sistemas, fornecem diretrizes para a resolução de conflitos - e isso resolve a questão. A abordagem teórica é convencida, ignorante, superficial, incompleta e desonesta. Ela é convencida porque presume que só os intelectuais têm ideias que valem a pena e que o único obstáculo para um mundo harmonioso é a discórdia entre seus níveis (FEYERABEND, 2010, p.35).

Essas adjetivações podem ser percebidas quando Lopes (2003, p. 45) compreende que "[...] fazer teoria passa a ser visto por intelectuais conservadores como um luxo reservado aos países ricos competindo a nós aplicar e consumir”. A afirmação reforça nossa condição de colonizado. A partir disso, pensamos: se o Brasil, em história recente, tentou ser um país emergente política e socialmente, por que não tornamos a pesquisa em Comunicação, com todas suas implicações, principalmente, as teórico-metodológicas, emergente? Uma hipótese é observar o alto índice de produtividade dos nossos pesquisadores em publicações, congressos e programas de pós-graduação. A observação de Lopes (2003) segue o conceito do capital intelectual, de Bourdieu, a quem Feyerabend se contrapõe por compreender que os intelectuais oferecem parcelas de conhecimento como tarefas convencidas de autovalorização. Nesse embate, Feyerabend (2011) diz que a ciência não pode ser um padrão do que se aceita ou não, do que se pode ou não.

Dizem que a análise social é uma questão difícil e que ela precisa de um discurso fortemente teórico para ter sucesso. Eu replico que um discurso teórico faz sentido nas ciências naturais, nas quais os termos abstratos são resumos de resultados prontamente disponíveis, mas que às afirmações teóricas sobre questões sociais muitas vezes faltam conteúdo e elas passam a ser ou absurdas ou superficialmente falsas quando o conteúdo é dado. (FEYERABEND, 2011, p. 332)

Quando Bourdieu (2004) aborda que toda produção teórica é o resultado de determinadas condições sociais, é plausível propor que neste novo contexto da Comunicação, de tecnologia digital, tal condição assuma nova posição na cultura. Abrese a possibilidade de existir solução teórica a esse intervalo ainda compreendido hegemonicamente pelas dicotômicas correntes estadunidenses e europeias.

As condições sociais geram um choque de culturas, como prevê Feyerabend (2010), com reações trazidas por dogmatismos, ou seja, os proponentes da produção teórica sempre acreditam que suas visões são mais corretas. A importação de teorias, no caso brasileiro, é muitas vezes um exercício sem crítica. Neste sentido, são duas as proposições de Feyerabend para a compreensão teórica, neste caso, aplicada à Comunicação: a primeira é que todo cientista, em busca de dinheiro, deve mostrar que 


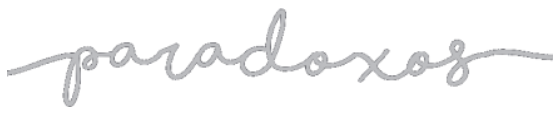

sua pesquisa traz ideias inovadoras que coincidam com os juízes que, por sua vez, também olham para sugestões inovadoras. Assim se estabelece o comum. A segunda é que a ciência progrida pela participação e não pelas teorias.

Esta acepção retoma um ponto que tem sido uma constante na formação científica: a concorrência que Thomas Kuhn (2009) trata como competição. A disputa, na comunidade científica, é o único processo histórico que rejeita uma teoria ou adota outra. $\mathrm{Na}$ Comunicação, nota-se isto, primeiro, pela variação de linhas de pesquisa em várias instituições que adotam um postulado teórico-metodológico na construção de um sentido, a partir de um autor referencial, central, ao qual muitas pesquisas se rendem. É preciso apontar, discutir e entremear ideias de autores, sim, com devidas ressalvas, e principalmente, crítica diante de preceitos e pressupostos. A melhor ferramenta para isso é o diálogo como método para que determinados autores não sejam sacralizados em suas verdades absolutas nos diversos objetos de estudo. O contraditório é um dos postulados da comunicação.

Uma forma de mensurar o trabalho do campo de conhecimento é incentivar as reformulações teóricas, algo que Lopes (2003) considera como lugar de formulação sistemática das hipóteses e dos conceitos, da definição da problemática e da proposição de regras de interpretação.

\footnotetext{
Criticar o empiricismo não é (a não ser por má-fé) fazer a defesa do teoricismo; é, antes, reconhecer a fraqueza do trabalho teórico no campo da Comunicação como a provável causa principal de nossa crise de identidade e da ausência de uma orientação substantiva em nossa pesquisa. O crescimento de um campo científico só se dá mediante o permanente confronto da teoria com os fatos, fatos esses que devem ser criteriosamente escolhidos e transformados em objetos científicos por meio da manipulação e elaboração intelectuais. (LOPES, 2003, p. 141)
}

Sobre Teorias da Comunicação, elas são paradigmáticas e não acompanham, na mesma proporção, a evolução social. A considerar, como Kuhn (2009), que o paradigma é uma realização científica, universalmente reconhecida por algum tempo diante de problemas e soluções modelares, em uma comunidade praticante da ciência, impossível pensar em Teorias da Comunicação apenas pela visão paradigmática das noções baseadas na estrutura emissor-mensagem-receptor, ampliada pelos efeitos da fórmula de Lasswell que deu atenção aos efeitos. De nada adianta produzir novas teorias a esmo sem entender por que o campo precisa de repaginação teórica.

A mudança depende de atitude e consciência. Kuhn (2009) afirma que a visão do homem depende do que sua experiência visual-conceitual prévia o ensinou a ver. Por isso, tratar da Revolução Científica, sugerida pelo autor, depende dos sujeitos. Muitos, talvez, DOI: http://doi.org/10.14393/par-v5n1-2020-53796 - Paradoxos, Uberlândia, v. 5, n. 1, p. 5-19, jan./jun. 2020 | 14 


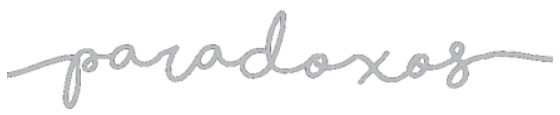

Os emaranhados da Comunicação pelas noções de campo, ciência e interdisciplinaridade

GABRIOTI, 2020

ainda não tenham se dado conta de que há um estopim para essa revolução, a qual nasce de um episódio extraordinário modificador da tradição para retornar à nova atividade da ciência normal. Para revolucionar, o cientista rejeita uma teoria científica anteriormente aceita em favor de outra incompatível com aquela. O nosso estopim, na Comunicação, parece estar nessa nova ordem tecnológica do digital, provocadora de significativas mudanças das formas e trocas simbólicas, ressignificadas pelo que Lorenzo Vilches (2001) chama de nova ordem social e cultural do século XXI. Sinais para isso não faltam. Basta considerar, por exemplo, que no exato momento de produção deste artigo, em abril de 2020, estamos assistindo a tecnologia mediar a interação humana, por todo o globo, em vários aspectos como relações sociais, relações do trabalho e novos consumos de Educação, em meio à pandemia do coronavírus.

A pesquisa paradigmática inibe a revolução científica e Kuhn (2009) aborda que quando os homens seguem regras e padrões, estão comprometidos com a prática científica da ciência normal mantendo a gênese e a continuação de uma tradição de pesquisa determinada cuja crise paradigmática está no funcionalismo da ortodoxa ação dos efeitos, baseada na construção singular de emissor, mensagem e receptor. Se, por um lado, Sodré (2014) aponta isso como camisa de força teórica que impõe um baixo avanço cognitivo nas pesquisas, por outro, critica as feições do pluralismo disciplinar (interdisciplinaridade, multidisciplinaridade e transdisciplinaridade), decorrentes dos anos 1960, por sintomas teóricos de uma crise de paradigma do conhecimento. Assertiva que discordamos. Se o rompimento de paradigmas, sustentado pela revolução científica, depende de novos planos conceituais estabelecidos por um olhar retroativo seguro do pesquisador, não há como dissociar a Comunicação de suas experiências e relações com outros campos do saber, estabelecidos pelas vivências. Nossa crise não está na abertura ao interdisciplinar, mas sim, na falta de nossa introspecção como autorreflexão para defender soberanamente a Comunicação, priorizada pela Linguagem, frente às outras instâncias de conhecimento.

Um paradigma só se invalida quando tem uma alternativa de substituição. E como pensa Kunh (2009), quem rejeita um paradigma, sem ter com o que substituí-lo, rejeita a própria ciência. A Comunicação entra nessa encruzilhada, mas com uma luz no fim do túnel. 
altera algumas das generalizações teóricas mais elementares do paradigma, bem como muitos de seus métodos e aplicações. (KUHN, 2009, p. 116)

Vivemos, na Comunicação, essa adequação paradigmática em que pesquisadores inserem os contextos em um mesmo modelo. Houve uma nova tentativa de reconstruir paradigmas ao dizer que a Comunicação se alterou com o fato de todos conseguirem produzi-la em função do acesso aos dispositivos móveis tecnológicos. Porém esse encantamento de facilidades do digital não pode simplesmente "jogar fora" todos os paradigmas para redesenhar o campo teórico da Comunicação. Evidentemente existe facilidade, por um lado, mas por outro há questões, como as socioeconômicas. Para acessar a Internet, por meio de dispositivo, há toda uma cadeia por trás. Sem um dispositivo adequado, ou um plano de Internet, um conhecimento prévio do uso do aparelho, etc. se torna difícil atingir uma presumida libertação.

Kuhn (2009) diz que, às vezes, os paradigmas impedem trabalhar com a razão e enquanto são aceitos, os problemas são dotados de uma solução possível por representarem segurança. Assim, se torna mais fácil reduzir qualquer prática comunicacional a uma noção de efeito ou tentar desmistificar a cultura de massa por meio da tecnologia contemporânea que permitiu o acesso aos indivíduos. E assim a Comunicação vive sua crise teórica justamente porque o paradigma ainda pretende explicar os fenômenos.

[...] os estudantes de ciência aceitam as teorias por causa da autoridade do professor e dos textos e não devido às provas. Que alternativas, que competência possuem eles? As aplicações mencionadas nos textos não apresentadas como provas, mas porque aprendê-las é parte do aprendizado do paradigma que serve de base para a prática científica em vigor. (KUHN, 2009, p. 111)

Cada pesquisador tem uma vivência levada junto a linhas de pesquisa que permeiam categorias de trabalho em modelos pré-estabelecidos nas universidades. Como diz Calhoun (2012, p.305), "os programas de Comunicação vivem na constante tensão entre o que os alunos querem estudar e o que seus professores querem ensinar".

De modo geral, a observação é primordial no trabalho do cientista por se tratar do ponto inicial de sua atividade. A observação gera descobertas, aplicações, mundos e vivências simbólicas de referenciais, metodologias, dados coletados e exame, por meio de análises. Logo os objetos da Comunicação são observáveis e podem gerar conhecimento e grandes ensaios.

Se a Ciência da Comunicação carrega a pecha de ser intangível, o nosso sistema educacional, em especial, pelos Programas de Pós-Graduação, pode descaracterizar isso 
pela legitimação. A formação científica de pesquisadores é essencial nesse processo. Por isso, é preciso valorizar o "santo de casa" diante dos autores-chave, em evidência no meio acadêmico; ir além dos relatórios com números, prazos e metas para conscientizar futuros pesquisadores que fazemos Ciência; discutir mais as pesquisas, pensando como são feitas e não quantas são feitas para refletir teoricamente a Área. De tudo, o recomeço parece ser estrutural e pedagógico.

\section{Considerações Finais}

De todo esse emaranhado em que campo, ciência e interdisciplinaridade se entrecruzam e confundem a construção de um conceito para a Comunicação; e desse resgate bibliográfico produzido, a tendência está mais fundamentada na noção de que a Comunicação é um campo porque seus pesquisadores mantêm a autoridade em guetos estabelecidos. Sobre as outras duas possibilidades, a interdisciplinaridade não é opcional em face do cruzamento com as outras Áreas de conhecimento. E como a Ciência exige refutar os paradigmas, essa condição se dificulta pelo comodismo teórico que bloqueia novas movimentações em busca da renovação das teorias.

Especificamente a Ciência da Comunicação ainda não está efetivamente legitimada porque falta alternativa consistente a tudo que já está construído. Seu postulado teórico parece "imortalizado" em manuais - quase sempre com as mesmas fontes - aos quais se consultam para saber onde os fenômenos, por mais atuais que sejam, se enquadram melhor. Na Comunicação, seguimos atendendo à ciência normal, pesquisando dentro dos mesmos formatos e padrões.

A tecnologia, e agora, o mundo com essa pandemia da Covid-19, colocam todos à prova das mesmas fragilidades. Os "patriotismos teóricos" talvez não façam mais sentido em um futuro mais do que breve. A atualidade nos escancara outra condição social. A primeira que nos está sendo dada, como humanos, é de que somos todos iguais diante da mesma ameaça. Se as Ciências Sociais e Humanas estiverem olhando para isso e entendendo alguns postulados, como os de Pierre Bourdieu, que apontou lá atrás sobre a condição social para propor teorias, e os de Paul Feyerabend, sobre a participação na Ciência, certamente, uma oportunidade está em curso e o emaranhado, até agora estruturado no campo, pode fazer da Comunicação, uma Ciência. 


\section{Referências}

BACHELARD, Gaston. A formação do espírito científico: contribuição para uma psicanálise do conhecimento. Rio de Janeiro: Contraponto, 1996. 316p.

BACHELARD, Gaston. Ensaio sobre o conhecimento aproximado. Tradução Estela dos Santos Abreu. Rio de Janeiro: Contraponto, 2004. 318p.

BOURDIEU, Pierre. Le Champ Scientifique. Actes de la Recherche en Sciences Sociales. In: ORTIZ, Renato; FERNANDES, Florestan. Sociologia. São Paulo: Ática, 1983.

BOURDIEU, Pierre et al. Ofício de sociólogo: metodologia de pesquisa na sociologia. Tradução João de Freitas Teixeira. Petrópolis: Vozes, 2004. 328p.

BRAGA, José Luís. A prática da pesquisa em comunicação: abordagem metodológica como tomada de decisões. E-Compós: Revista Eletrônica da Associação Nacional dos Programas de Pós-Graduação em Comunicação, Brasília, v.14, n.1, p.1-33, jan./abr. 2011.

CALHOUN, Craig. Comunicação como ciência social (e mais). Revista Brasileira de Ciências da Comunicação: Revista da Sociedade Brasileira para os Estudos Interdisciplinares dos Estudos em Comunicação (Intercom), São Paulo, v.35, n.1, p 277-310, jan./jun. 2012.

DILTHEY, Wilhelm. A construção do mundo histórico nas ciências humanas. São Paulo: UNESP, 2010. Tradução Marco Casanova. 346p.

FEYERABEND, Paul. Adeus à razão. São Paulo: UNESP, 2010. 399p.

GABRIOTI, Rodrigo. A FAPESP e a Ciência da Comunicação: Legitimação, Contribuição e Construção da Área. Tese (Doutorado em Comunicação Social) Escola de Comunicação, Educação e Humanidades da Universidade Metodista de São Paulo, São Bernardo do Campo, 2018. 349 p.

GARCÍA, Rolando. Sistemas complejos: conceptos, método y fundamentación epistemológica de la investigación interdisciplinaria. Barcelona: Gedisa, 2006. 200p.

GONZÁLEZ, Jorge A. Entre cultura(S) e cibercultur@(S): incursões e outras rotas não lineares. São Bernardo do Campo: Universidade Metodista de São Paulo, 2012. 265p.

HAAG, Carlos. A crise da média idade. Revista Pesquisa FAPESP. São Paulo, 211. ed. p.77-81, 2013

KUHN, Thomas. A estrutura das revoluções científicas. São Paulo: Perspectiva, 2009.

LOPES, M.I.V. Pesquisa em comunicação. 7.ed. São Paulo: Loyola, 2003. 171p. 
LOPES, M.I.V. A institucionalização da pesquisa em comunicação. Epistemologia do Campo da Comunicação no Brasil. In: $40^{\circ}$ CONGRESSO BRASILEIRO DE CIÊNCIAS DA COMUNICAÇÃO (INTERCOM), 2017, Curitiba.

MARQUES DE MELO, José. Teoria e metodologia da comunicação: tendências do século XXI. São Paulo: Paulus, 2014. 542p.

MORIN, E. Ciência com consciência. 13. ed. Rio de Janeiro: Bertrand Brasil, 2010, 341p.

MOURA, Mariluce. José Marques de Melo: A prima pobre das ciências sociais. Revista Pesquisa Fapesp. 201. ed. São Paulo, p.26-33, nov. 2012.

SODRÉ, Muniz. A ciência do comum: notas para o método comunicacional. Petrópolis: Vozes, 2014. 323p.

SODRÉ, Muniz. Comunicação: um campo em apuros teóricos. MATRIZes: Revista do Programa de Pós-Graduação em Comunicação da Universidade de São Paulo. São Paulo, v.5, p.11-27, 2012.

VICLHES, Lorenzo. A migração digital. São Paulo: Puc Rio; Loyola, 2003. 